\title{
Psychosocial and medical factors affecting treatment compliance in patients attending psychiatric hospital: a study from Kashmir
}

\author{
Sheikh Shoib ${ }^{1}$, Raheel Mushtaq ${ }^{1}$, Mohammad Maqbool Dar ${ }^{1}$, Javid Ahmad Mir ${ }^{1}$, \\ Tabindah Shah ${ }^{2}$, Rameshwar Singh ${ }^{1}$, Javid Ahmad ${ }^{3}$, Syed Kyser ${ }^{4}$
}

\author{
${ }^{1}$ Department of Psychiatry, GMC \\ Srinagar - 190010, Jammu and \\ Kashmir, India, \\ ${ }^{2}$ M.B.B.S., GMC Srinagar-190010, \\ Jammu and Kashmir, India, \\ ${ }^{3}$ Department of Community \\ Medicine, SKIMS Soura, Srinagar \\ - 190011, Jammu and Kashmir, \\ India, \\ ${ }^{4}$ Assitant Surgeon, GMC Srinagar - \\ 190010, Jammu and Kashmir, \\ India
}

Received: 27 October 2013 Accepted: 13 November 2013

*Correspondence to:

Dr. Sheikh Shoib,

Email: sheikhshoib22@yahoo.com

(C) 2014 Shoib S et al. This is an open-access article distributed under the terms of the Creative Commons Attribution NonCommercial License, which permits unrestricted noncommercial use, distribution, and reproduction in any medium, provided the original work is properly cited.

\begin{abstract}
Background: Compliance with medication is decisive for treatment of the psychiatric disorders and is necessary for determining the outcome and prognoses of psychiatric patients. While the causes of poor compliance are multifactorial, the psychiatrist should be aware of such factors and may be able to implement interventions to address those factors. The objective of study was to find out the various medical and social reasons affecting treatment Compliance among patients suffering from psychiatric disorders.

Methods: A Cross-Sectional study from 2011 to 2012 was conducted in IMHANS (Institute of Mental Health and Neurosciences) Srinagar (J\&K), a questionnaire was designed, and the questionnaire included questions on socio-demographic variables, psychiatric illnesses, and Medical and psychosocial affecting treatment compliance. A systematic selection method for choosing the respondents was opted, questionnaire was administered on 200 $(n=200)$ patients who attended the Outpatient department during the period. Simple random sampling method was applied for selection of respondents, the first time visitors to OPD were exclude along with repetition of respondents.

Results: Out of 200 respondents studied in the study $41.5 \%$ were males and $58.5 \%$ were females. Maximum number of patients $(31.5 \%)$ studied were in the age group below the 30 years. $3.5 \%$ of respondents were in the age group above 70 years. Out of total 200 respondents in the study $74 \%$ of the respondents are in compliance with recommended medicine whereas noncompliance was found in the $26 \%$ of studied population. Complications $(13.46 \%)$ ascending out by usage of psychiatric medicine can be attributed as one of the major case of treatment non-compliance in psychiatric patients, among the psychiatric patients. Accessibility of psychiatric medicine and Financial constrain was also one of the reasons behind the medicine noncompliance $(7.69 \%)$. Patients with no insight to psychiatric disease also include a good percentage of $(5.76 \%)$ of medicine non- compliance.

Conclusions: Non-compliance is a dominant factor which causes possibly causes readmission in psychiatric wards. Compliance in psychiatric patients in general could be enhanced and improved by adequate intervention via patient counselling and patient medicinal care and education.
\end{abstract}

Keywords: Psychiatric medicine, Medical factors, Social factors

\section{INTRODUCTION}

Compliance is the extent to which a patient complies with the prescribed medicine by a health professional. It is extent to which a person's behaviour confirms to medical or health advice. ${ }^{1}$ The opposite of this process of adherence is also true but is an issue leading to relapse and rehospitalisation among the patients. Patients who don't follow the treatment schedule and drug regimens prescribed to them by physician can be described as noncompliant or not adherent. ${ }^{2}$ Medications nonadherence is an issue associated with all diseases and in all populations, with patients suffering from psychiatric 
illness being more susceptible. ${ }^{3}$ The dropout rate is attributed to various factors including demographic ones so it becomes imperative to make an in-depth systematic study to explicit the reasons of non-compliance among psychiatric patient population of a particular topographical region, Estimates of medicine noncompliance ranges between $4 \%$ and $92 \%$ with average from 30 to 35 percent. $^{4}$ Like other diseases Compliance with antipsychotic medication is crucial for treatment of the psychiatric problems. Adherence is necessary for sustainable medical intervention. ${ }^{4}$ Keeping these points in view, to find out reason of poor drug compliance, a prospective exploratory study was conducted at the outpatients department The objective of this study was to find out the different reasons of the medicine non-compliance among the psychiatric patients.

\section{METHODS}

A cross-sectional study from 2011 to 2012 was conducted in IMHANS (Institute Of Mental Health And Neurosciences) Srinagar (J\&K), with an objective to study the various medical and social reasons affecting treatment Compliance among patients suffering from psychiatric disorders. An inclusive questionnaire was designed to explicit the reasons of Medicine non adherence among psychiatric Patients. This mixed questionnaire included questions on socio-demographic variables, psychiatric illnesses, and Medical and psychosocial reasons. Questionnaire was with predominance of open ended questions so as to fit the diverse response on non-compliance. After screening guardians as well as patients verbal consent were taken before conducting the study. A systematic selection method for choosing the respondents was opted, questionnaire was administered on $200(n=200)$ patients who attended the OPD during the period. Simple random sampling method was applied for selection of respondents, the first time visitors to OPD were exclude along with repetition of respondents. Efforts were made to record the diverse response from the patients. The outcome reasons were classified into two main categories as Medicinal reasons and psychosocial reasons Data tabulation and processing was carried by SPSS.

\section{RESULTS}

Out of total 200 respondents in the study $74 \%$ of the respondents are in compliance with recommended medicine whereas non-compliance was found in the $26 \%$ of studied population. In-depth reasons leading to noncompliance were explicated out and categorised into medical and psycho social reasons.

\section{Characteristics of respondents}

Characteristics of respondents have been presented in Table 1.
Table 1: Demographic characteristics of the studied patients.

\begin{tabular}{|c|c|c|c|}
\hline \multicolumn{2}{|c|}{ Characteristic } & $\mathbf{N}$ & $\%$ \\
\hline & $\leq 30$ & 63 & 31.5 \\
\hline \multirow{6}{*}{ Age (year) } & 31 to 40 & 52 & 26.0 \\
\hline & 41 to 50 & 33 & 16.5 \\
\hline & 51 to 60 & 18 & 9.0 \\
\hline & 61 to 70 & 27 & 13.5 \\
\hline & $>70$ & 7 & 3.5 \\
\hline & mean $\pm \mathrm{SD}$ & $\begin{array}{l}50.4 \\
(18,\end{array}$ & \\
\hline \multirow{2}{*}{ Gender } & Male & 83 & 41.5 \\
\hline & Female & 117 & 58.5 \\
\hline \multirow{2}{*}{ Dwelling } & Rural & 140 & 70.0 \\
\hline & Urban & 60 & 30.0 \\
\hline \multirow{3}{*}{$\begin{array}{l}\text { Marital } \\
\text { status }\end{array}$} & Unmarried & 12 & 6.0 \\
\hline & Married & 153 & 76.5 \\
\hline & Widowed & 35 & 17.5 \\
\hline \multirow{5}{*}{ Occupation } & Household & 109 & 54.5 \\
\hline & Unskilled & 32 & 16.0 \\
\hline & Semiskilled & 33 & 16.5 \\
\hline & Skilled & 24 & 12.0 \\
\hline & Professional & 2 & 1.0 \\
\hline \multirow{3}{*}{ Family type } & Nuclear & 91 & 45.5 \\
\hline & Joint & 43 & 21.5 \\
\hline & Extended & 66 & 33.0 \\
\hline \multirow{6}{*}{$\begin{array}{l}\text { Literacy } \\
\text { status }\end{array}$} & Illiterate & 149 & 74.5 \\
\hline & Primary & 7 & 3.5 \\
\hline & Secondary & 11 & 5.5 \\
\hline & Matric & 23 & 11.5 \\
\hline & Graduate & 9 & 4.5 \\
\hline & $\begin{array}{l}\text { Postgraduate } \\
\text { /Professional }\end{array}$ & 1 & 0.5 \\
\hline \multirow{4}{*}{$\begin{array}{l}\text { Family } \\
\text { income (Rs) }\end{array}$} & $<5000$ & 30 & 15.0 \\
\hline & $\begin{array}{l}5000 \text { to } \\
10000\end{array}$ & 141 & 70.5 \\
\hline & $\geq 10000$ & 29 & 14.5 \\
\hline & mean $\pm \mathrm{SD}$ & $\begin{array}{l}840 \\
(200\end{array}$ & \\
\hline \multirow{5}{*}{$\begin{array}{l}\text { Socioecono } \\
\text { mic status } \\
\text { (Kuppuswa } \\
\text { my Scale ) }\end{array}$} & Lower & 10 & 5.0 \\
\hline & Upper lower & 122 & 61.0 \\
\hline & Middle & 49 & 24.5 \\
\hline & $\begin{array}{l}\text { Upper } \\
\text { middle }\end{array}$ & 18 & 9.0 \\
\hline & Upper & 1 & 0.5 \\
\hline
\end{tabular}

\section{Diagnosis}

Various psychiatric disorders suffered by the population under current study have been presented in Table 2 and Figure 1.

Current study revealed that collectively $39.5 \%$ of the respondents were diagnosed of suffering from schizophrenia and schizoaffective disorders $(26 \%$ schizophrenia, $14.5 \%$ schizoaffective) Bipolar disorders 
constitute $19 \%$ whereas $15.5 \%$ of the respondents have been diagnosed as suffering from MDD. OCD was diagnosed in $11 \%$ and $5.5 \%$ of population was found to be affected by seizure disorders.

Table 2: Various psychiatric disorders suffered by the population.

\begin{tabular}{|ll|}
\hline Type of psychiatric problem & Percentage \\
\hline Schizophrenia & $26 \%$ \\
\hline Schizoaffective & $14.5 \%$ \\
\hline Bipolar disorders & $19 \%$ \\
\hline MDD & $15.5 \%$ \\
\hline OCD & $11 \%$ \\
\hline Seizure disorders & $5.5 \%$ \\
\hline Others & $8.5 \%$ \\
\hline
\end{tabular}

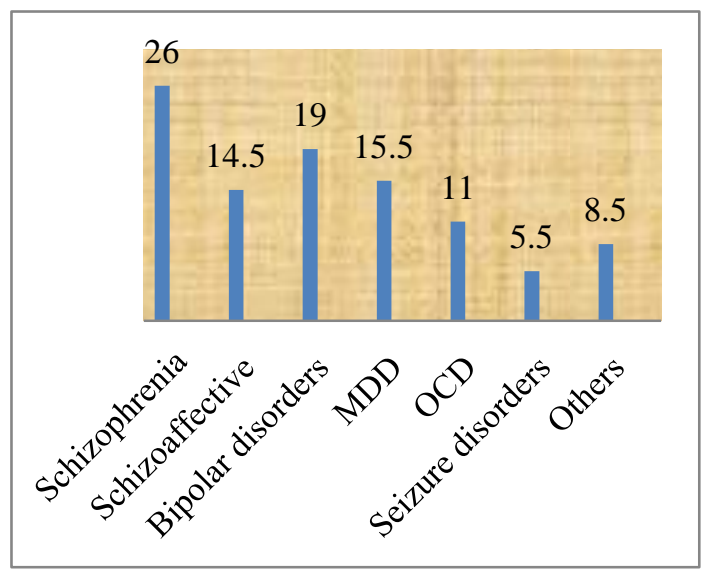

Figure 1: Types of psychiatric problems diagnosed.

\section{Characteristics of respondents}

Out of 200 respondents studied in the study $41.5 \%$ were males and $58.5 \%$ were females. Respondents from both rural and urban regions of the state represented the respondent population. Maximum number of patients $(31.5 \%)$ studied were in the age group below the 30 years, minimum percentage of $3.5 \%$ of respondents were in the age group above 70 years. Age group of 31-40 years is the second highest percentage of respondents included in the study. $54.5 \%$ of the respondents were engaged in Household work with more number of female subcategory in this category. Unskilled labours constituted $16.0 \%$, earning their livelihood through daily wage based works, another $16.5 \%$ were Semiskilled labours with slight advantage over unskilled in terms of income generation, Skilled labour included $12.0 \%$, a small population of respondents $(1 \%)$ were found to be Professional in different trades, with sustainable and sound family incomes. $74 \%$ of respondent population has been found to be illiterate.

\section{Medical reasons}

Medication Complications (13.46\%) and addiction to medicines $(7.6 \%)$ were the most important factors noted to be responsible for non-compliance due to medical reasons (Table 3 and Figure 2).

Table 3: Medical reasons of non-compliance.

\begin{tabular}{|ll|}
\hline Medical reasons of non-compliance & Percentage \\
\hline Medication complications & $13.46 \%$ \\
\hline Addiction to medication & $7.69 \%$ \\
\hline Because of no insight to disease & $5.76 \%$ \\
\hline Because of feeling of cure & $5.76 \%$ \\
\hline Paranoia to medication & $3.84 \%$ \\
\hline $\begin{array}{l}\text { Decreased function and activity of } \\
\text { daily life }\end{array}$ & $3.84 \%$ \\
\hline Because of many medications & $5.76 \%$ \\
\hline
\end{tabular}

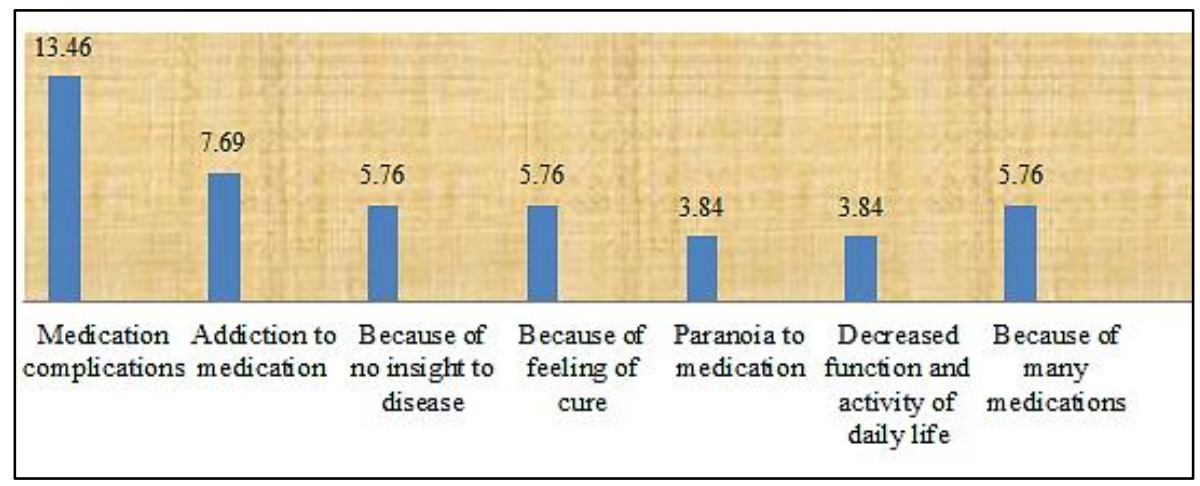

Figure 2: Medical reasons of non-compliance.

\section{Psychosocial reasons}

Faith healer $(9.61 \%)$, lack of family education $(7.69 \%)$, and no insight to illness $(7.69 \%)$ were the most important psychosocial reasons for non-adherence to psychiatric medicines (Figure3 and Table 4). 


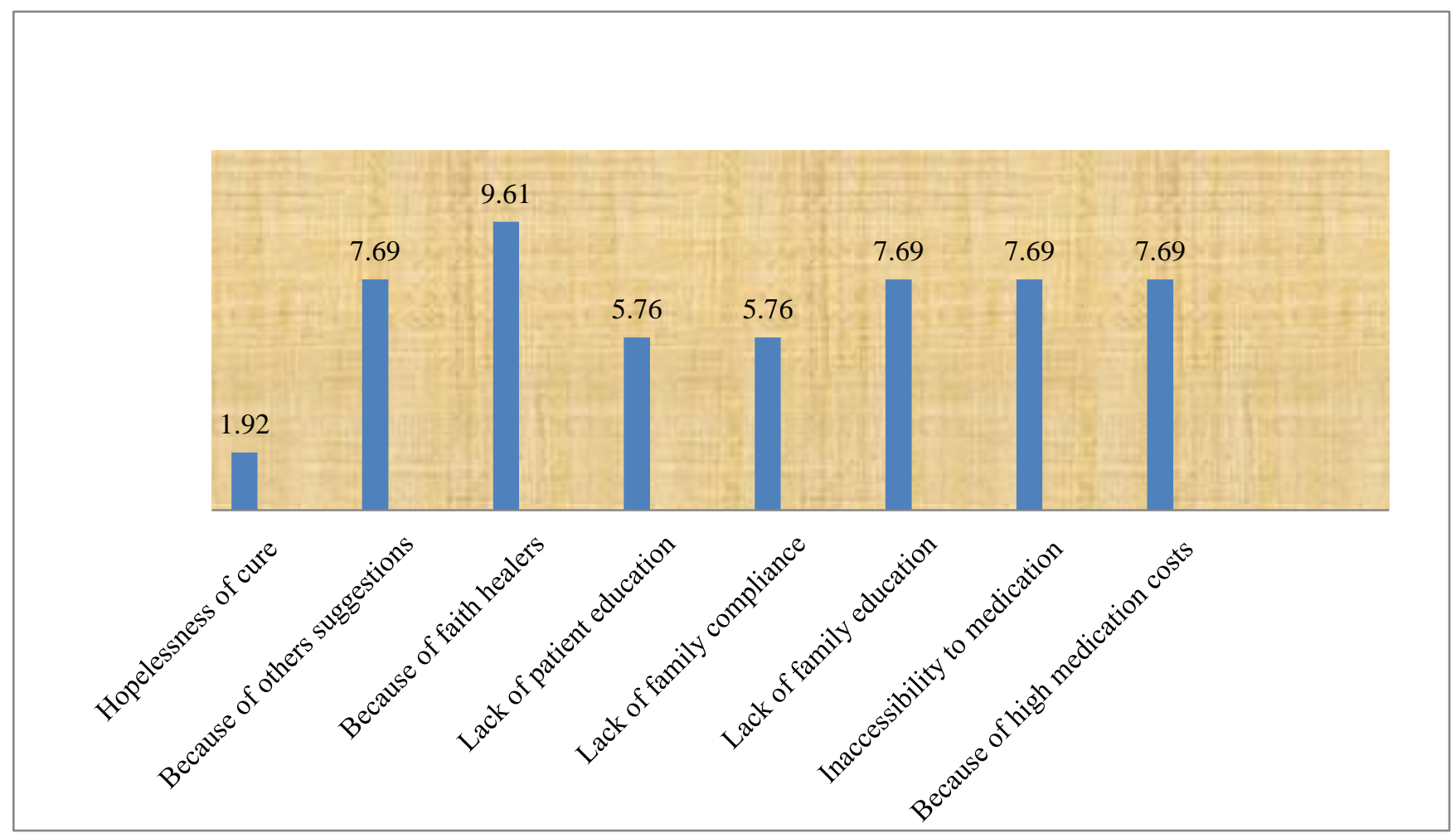

Figure 3: Psychosocial reasons.

Table 4: Psychosocial reasons.

\begin{tabular}{|ll|}
\hline Psychosocial reasons & Percentage \\
\hline Hopelessness of cure & $1.92 \%$ \\
\hline Because of others suggestions & $7.69 \%$ \\
\hline Because of faith healers & $9.61 \%$ \\
\hline Lack of patient education & $5.76 \%$ \\
\hline Lack of family compliance & $5.76 \%$ \\
\hline Lack of family education & $7.69 \%$ \\
\hline Inaccessibility to medication & $7.69 \%$ \\
\hline Because of high medication costs & $7.69 \%$ \\
\hline
\end{tabular}

\section{DISCUSSION}

The objective of this study was to find out the different factor affecting treatment compliance among the psychiatric patients. Efforts were made to record the diverse response from the patients. The outcome reasons were classified into two main categories as Medicinal reasons and psychosocial reasons. In our study it is clear that more than one factor is responsible for poor or better compliance of therapeutic regimen. Among the first category the medication complications contributes the highest percentage of $13.46 \%$ in our study, the complications included an array of unpleasant side effects are known to be associated with most of the psychotropic medicines responsible for enhancing the rate of non-adherence in different studies. ${ }^{5,6}$ These finding are in accordance with Fakhoury et al (1999 and 2001).
One of the prominent factors to contribute to poor compliance in individuals with psychiatric disorders includes lack of insight to disease (5.76\%). Rittmannsberger et al (2004) predicted low insight with poor compliance and improvements is accompanied by good compliance rate. ${ }^{7}$

Our study revealed that about $7.69 \%$ of the non-adherent patient population did not follow medication due to feeling of getting addicted to psychiatric medicine. Hopelessness of cure accounted $1.92 \%$ of noncompliance behaviour. Slowness of rate of body activities by some of the psychotropic medicines is perceived to be threatening by the patients and effect triggers discontinuation of medicine and contributed $3.84 \%$ in our study population. Delayed curing capacity of drug therapy and polypharmacy contributed $5.76 \%$ of population. Perkin et al. (2006) have shown that disbelief of the recommendations of health professional by the patients is correlates with poor adherence regime. ${ }^{8}$

The belief on those faith healers who are disbelievers of psychotropic medicine has been found to increase the chances of non-compliance in current study. This factor contributes an alarming percentage of $9.61 \%$ as the cause of non-adherence among patients suffering from psychiatric diseases. Kashmir is the place of Sufis and saints, and there local faith healers as peer and faqirs which are important representatives of our religion, they have wisdom to give advice and treatment regarding various mental and psychical illness. Thus the belief in spiritual causation may affect treatment compliance as 
patients and caregivers believe more in spiritual causation and their solution to resolve their mental illness and therefore affect treatment compliance. ${ }^{9,10}$

Compliance from the family members is also a dependent factor in non-adherence as has been revealed in the current study 7.76 of the patients discontinued the medication when there is lack of family compliance. ${ }^{11}$ The family compliance may reinforce medication usage, and this therefore creates a therapeutic chain of events. ${ }^{12}$

Inaccessibility of psychotropic medicine is a grave issue especially in the rural topographical regions. Curfew and Hartal (Complete shutdown of shops, and transport) due to present turmoil are common in Kashmir. ${ }^{13}$ Kashmir is a place of continuous turmoil and conflict and inaccessibility of psychiatric medicine is important factor responsible for non-adherence. Convenient mode of transportation was not available in many far flung places of Kashmir.

Although patients can buy medicine from local shops, Inaccessibility of psychotropic medicine is main problem in remote areas and contributed 7. $69 \%$ of patients attributed the cause of non-adherence to inaccessibility of medicine and due to high cost. Among the economic causes the low economic status played a pivotal role in increasing the rate of non-adherence. Lack of basic infrastructure is associated with poor compliance treatment and thus advocates need of community level services related to mental health care. ${ }^{14}$

From the above findings it is now clear that multiple factors are responsible for non-adherence to psychiatric medications. There is a need to provide community level mental health care and proper counselling to patients and their caregivers.

Non-compliance is a dominant factor which causes possibly causes readmission in psychiatric wards. Compliance in psychiatric patients in general could be enhanced and improved by adequate intervention via patient counselling and patient medicinal care and education.

\section{Funding: No funding sources}

Conflict of interest: None declared

Ethical approval: The study was approved by the institutional ethics committee

\section{REFERENCES}

1. Bruer JT. Methodological rigor and citation frequency in patient compliance literature. American Journal of Public Health. 1982;72:911-1123.

2. Razali, MS, Yahya H. Compliance with treatment in Schizophrenia: A drug intervention program in a developing country. Acta Psychiatrica Scandinavica. 1995;91:331-5.

3. Nageotte C, Sulliman G, Duan N, Camp PL. Medication compliance among the seriously mentally ill in a public health system. Social Psychiatry and Psychiatric Epidemiology 1997;32:49-56.

4. Feuertein, M., E.E. Labbe, \& A.R. Kuegmierezyk. Health Psychology: A Psychobiological Perspective. New York: Pleneum Press; 1986.

5. Fakhoury, W. K. Extent of distress caused by adverse experiences associated with anti-psychotic treatment (abstract). European Neuropsychopharmacology. 1999;9(suppl.5):S131390.

6. Fakhoury, W. K., Wright, D. \& Wallace, M. Prevalence and extent of distress of adverse effects of antipsychotics among callers to a United Kingdom National Mental Health Helpline. International Clinical Psychopharmacology. 2001;16:153-62.

7. Rittmannsberger, H., Pachinger, T., Keppelmuller, P., et al. Medication adherence among psychotic patients before admission to inpatient treatment. Psychiatric Services. 2004;55:174-9.

8. Perkins DO. Predictors of noncompliance in patients with schizophrenia. J Clin Psychiatry. 2002;63:11218 .

9. Adewuya AO, Owoeye OA, Erinfolami AR, Ogun OC, Dada AU, Akindipe TO. Prevalence and correlates of poor medication adherence amongst psychiatric outpatients in southwestern Nigeria. Gen. Hosp. Psychiatr. 2009;31:167-74.

10. Huda M, Mustaq MA. Pir Faqir and psychotherapist: Their role in psychosocial intervention of trauma. JK practitioner. 2006;13 (suppl 1):s89-93.

11. Daltroy, L., Katz, J., Morlino, C. et al. Improving doctor patient communication. Psychiatric Medicine. 1991;2:31-5.

12. Fenton WS, Blyler CR, Herrissen KK. Determinants of medicinal compliance in schizophrenia, empirical and clinical findings. Schizophrenia Bull. 1997;23:637-51.

13. Shoib S, Dar MM, Bashir $\mathrm{H}$ et al. Psychiatric morbidity and the socio-demographic determinants of patients attempting suicide in Kashmir valley: a cross-sectional study. Int $\mathbf{J}$ Health Sci Res. 2012;2(7):45-53.

14. Roy R, Jahan M, Kumari S, et al. Reasons for Drug Non-Compliance of Psychiatric Patients: A Centre Based Study. Journal of the Indian Academy of Applied Psychology. 2005 January-July;31(1-2):248.

doi:10.5455/2319-2003.ijbcp20140230

Cite this article as: Shoib S, Mushtaq R, Dar MM, Mir JA, Shah T, Singh R, Ahmad J, Kyser S.

Psychosocial and medical factors affecting treatment compliance in patients attending psychiatric hospitala study from Kashmir. Int J Basic Clin Pharmacol 2014;3:220-4. 